\title{
Analysis of The Influence of Big Data on The Cost Control of Tianbao Green Food Company
}

\author{
Zhou Xu ${ }^{1}$, Xiaoli Ji ${ }^{1}$, Junfeng Wang ${ }^{1}$, Tianyu Guo ${ }^{1}$ \\ ${ }^{1}$ Dalian University of science and Technology School of economics and Management Dalian
}

\begin{abstract}
In the era of big data, the cost control of enterprises is important, and the cost is still the main factor affecting the competitiveness of enterprises. Data information occurs in every part of an enterprise. If these data are collected reasonably and analyzed with professional software system, the effect of enterprise cost control could be quantified. This paper takes Tianbao green food company as an example, studies its cost control situation, summarizes the existing problems in cost control of the company, and analyzes how to use big data to control cost for purchasing, storage, producing and sales.
\end{abstract}

\section{INTRODUCTION}

With the development of economic globalization, the frequency of information exchange between enterprises increases significantly. Massive data needs to be analyzed to make the right development goals and achieve the stable growth of enterprises. Big data is the most effective analysis method among current analysis methods. As the name implies, big data is a technology for analyzing massive data, which relies on the distributed computer analysis structure to complete the analysis and mining of data. In the current process of enterprise development, cost is an important factor that restricts the development, profit, competition and other business activities of the enterprise. However, due to the diversified competition behavior faced by the enterprise in the operation process, its cost structure also presents diversified development. How to reasonably analyze and fully acknowledge cost date is of great practical value to optimize the cost structure and improve the comprehensive competitiveness of enterprises.

In the process of enterprise cost control, the traditional way of accounting mainly focused on cost structure and specific accounting as the main body of accounting behavior, and ignoring the enterprise cost in the process of the development trend and correlation analysis, which is difficult to achieve the enterprise cost forecast and making development plan for manager. Therefore, this paper takes Tianbao green food company as an example to study the existing problems in its cost control system, and proposes related solutions through big data technology.

\section{THE MEANING AND CHARACTERISTICS OF BIG} DATA

\section{A. The meaning of big data}

"Big data" is based on the knowledge of computer science, mathematical algorithm and other disciplines. It was first developed abroad the creation of "big data ", wrote by Victor Meyer Schonberg, is the earliest work to study big data technology. The main point of view is that big data, as a kind of technology that can process data in batches, can achieve the effectiveness of information processing in the massive information era caused by Information science in the future. As the most important resource in the 21 st century, information asymmetry is the key of market competitiveness. As the main carrier of information, data processing is directly related to the development of enterprises. Therefore, big data technology is widely used in the development of all walks of life. As the name implies, big data has a variety of data types, and data is the carrier of information, including a variety of information data, such as customer address, age, hobbies and other information. The analysis of the above data through big data technology can give full play to the maximum value of the data.

\section{B. Characteristics of big data}

Big data has four characteristics: large amount, various types, high value and fast processing speed. Large amount means a lot of data, including the breadth and depth of the data. Various types includes data information of all walks of life, such as price information, logistics information, purchase information, stock rise and fall information. High value means that once the big data information is integrated, analyzed and used, it can help enterprises predict the economic situation, measure the degree of market competition, understand the consumer's buying behavior, etc., and also bring certain benefits to the development of society. Fast processing speed means that in today's developed network, big data information can be acquired and processed in a short time, of course, this needs strong high-tech support.

\section{Problems of cost control of Tianbao COMPANY}

Tianbao green food company is a modern food enterprises, the main company's business scope is import and export business, operating the enterprise's processing services; 
Purchase, production, processing, sale and storage of agricultural and sideline products, aquatic products, soybean products, frozen food and quick-frozen food; High-tech agricultural technology research and development.

\section{A. Cost structure}

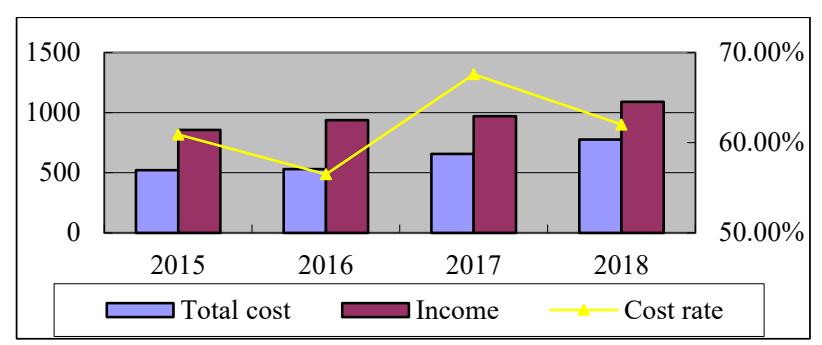

Figure I. Total Cost of The Company

Figure I shows that the total cost of Tianbao green food company has been rising from 2015 to 2018. Even though operating income is in a state of rise, but basic cost rate (total cost/revenue) is above $45.0 \%$, while the industry average of $30 \%$. Through comparison, cost management level of Tianbao company is not ideal, and there is still a big gap with the cost rate of the same industry.

TABLE I. COST EXPENDITURE IN 2015-2018 UNIT: 10000 YUAN

\begin{tabular}{|c|c|c|c|c|}
\hline Project & 2015 & 2016 & 2017 & 2018 \\
\hline Rent & 64.8 & 68.0 & 71.4 & 75.0 \\
\hline Raw material & 227.6 & 219.2 & 237.9 & 217.6 \\
\hline Beverage & 9.8 & 7.4 & 11.8 & 8.8 \\
\hline Wages & 107.7 & 99.1 & 109.6 & 111.7 \\
\hline $\begin{array}{l}\text { Recruitment and } \\
\text { training }\end{array}$ & 2.9 & 3.2 & 3.3 & 3.3 \\
\hline $\begin{array}{c}\text { Low value } \\
\text { consumables }\end{array}$ & 14.5 & 14.1 & 16.7 & 15.5 \\
\hline Hydropower & 14.8 & 15.2 & 15.5 & 15.8 \\
\hline Gas & 23.1 & 25.4 & 25.9 & 22.9 \\
\hline Other & 32.4 & 27.6 & 31.7 & 29.9 \\
\hline Total & 497.6 & 479.2 & 523.8 & 500.5 \\
\hline
\end{tabular}

TABLE II. PROPORTION OF COST AND EXPENSE IN 2018

\begin{tabular}{|c|c|c|c|}
\hline Project & Cost & Percentage & Rank \\
\hline Rent & 75 & $15.0 \%$ & 3 \\
\hline Raw material & 217.6 & $43.5 \%$ & 1 \\
\hline Beverage & 8.8 & $1.8 \%$ & 8 \\
\hline Wages & 111.7 & $22.3 \%$ & 2 \\
\hline $\begin{array}{c}\text { Recruitment and } \\
\text { training }\end{array}$ & 3.3 & $0.7 \%$ & 9 \\
\hline $\begin{array}{c}\text { Low value } \\
\text { consumables }\end{array}$ & 15.5 & $3.1 \%$ & 7 \\
\hline $\begin{array}{c}\text { Hydropower } \\
\text { Gas }\end{array}$ & 15.8 & $3.2 \%$ & 6 \\
\hline Other & 22.9 & $4.6 \%$ & 5 \\
\hline
\end{tabular}

Table I and table II show that the largest proportion of variable cost is raw material procurement cost, which has reached $43.5 \%$, ranking first in the proportion of cost and expense of the company in 2018, directly affecting the level of total operating cost. But raw material purchase cost can be controlled by the company to a large extent. If Tianbao green food company manages the raw material cost well, it can reduce the overall operating cost.

Among other cost expenditures, energy such as water, electricity and gas also need Tianbao company to invest a certain amount of capital, and is affected by various factors, the volatility is high, can be controlled by taking countermeasures to reduce its consumption as far as possible.

Alcoholic beverages and some low-value consumables will also consume certain costs. Although the value of individual products is relatively low, the large demand will also lead to a large amount of costs and expenses. It is necessary for the company to strengthen the cooperation with beverage suppliers and reduce the purchase price, thus reducing the cost in this aspect.

TABLE III. COST PROFIT MARGIN IN 2015-2018

\begin{tabular}{|c|c|c|c|c|}
\hline Project & 2015 & 2016 & 2017 & 2018 \\
\hline Cost & 497.6 & 479.2 & 523.8 & 500.5 \\
\hline Profit & 334.7 & 407.4 & 313.8 & 313.6 \\
\hline Cost-profit ratio & $67.3 \%$ & $85.0 \%$ & $59.9 \%$ & $62.6 \%$ \\
\hline
\end{tabular}

TABLE IV. OPERATING COST RATIO IN 2015-2018

\begin{tabular}{|c|c|c|c|c|}
\hline Project & 2015 & 2016 & 2017 & 2018 \\
\hline Operating cost & 520.3 & 528.6 & 655.2 & 775.4 \\
\hline Business income & 855 & 936 & 969 & 1089 \\
\hline Operating cost ratio & $60.9 \%$ & $56.5 \%$ & $67.6 \%$ & $71.2 \%$ \\
\hline
\end{tabular}

Table III and table IV show that the total cost of Tianbao company in 2018 has increased year by year, but the cost control situation has improved. The cost profit rate fluctuated a lot in these four years. In 2018, it recovered slightly, reaching $62.6 \%$, and the operating cost rate reached $71.2 \%$. It can be seen that although the company has taken some control measures and achieved initial results, it still needs to strengthen the control of relevant costs.

\section{B. Problems in the company's cost control}

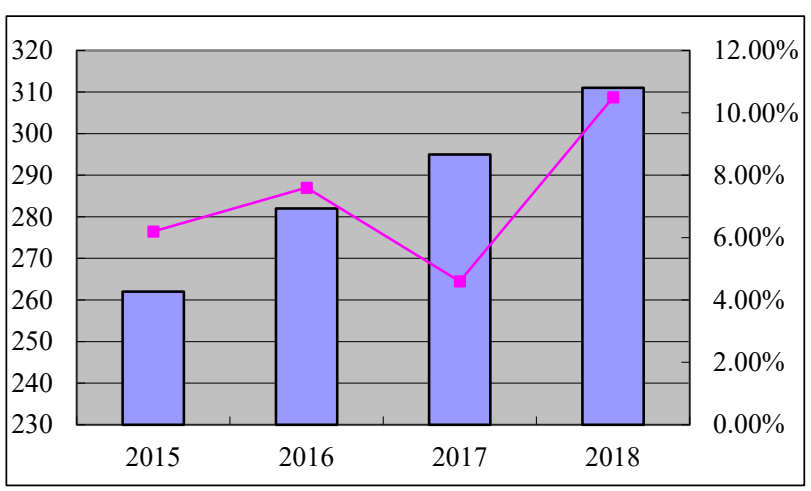

Figure II. Procurement cost from 2014 to 2017

1) Procurement cost control is not standardized: Tianbao company did not make a clear plan for the procurement cost control work, and the work of the procurement personnel was more casual, lacking the connection between the procurement link, inventory and 
production and processing link, resulting in the shortage or waste of materials. Food and beverage enterprises have complex requirements for raw materials, and require purchasing personnel to have high purchasing skills, so as to minimize the cost of purchasing in the work. However, the purchasing skills of Tianbao company's purchasing personnel are insufficient, the internal distribution work is relatively vague, the purchasing personnel lack the ability to identify raw materials, and there are fraud behaviors between purchasing personnel and suppliers. In 2015, the company's procurement cost was 2.62 million, reaching 3.26 million by 2018 , with rapid growth, as shown in Figure II.

2) The imperfection of cost control system of production and processing: Tianbao company did not establish a complete cost control system for the production and processing links, which led to various problems in the process of food processing, such as the shortage of raw materials at the end of the year, the production staff arbitrarily change the proportion of food raw materials, leading to the dissatisfaction of the business. Sometimes production personnel in order to reduce the workload during the peak period, the raw materials will be processed into finished products in advance, and will be part of the storage, when the needs of the business when the secondary processing, to facilitate rapid production. This practice not only damages the taste of food, but also often results in some finished materials deteriorating after long-term storage, unable to be reused, resulting in greater waste. In the transportation link after processing, the cost control is very weak, the transportation cost is high.

3) Low inventory cost control level: Tianbao company has arranged special personnel to check and accept the warehousing materials, but it has not supervised the warehouse keeper well, which is easy to cause the warehouse keeper to report more losses and increase the cost of warehouse keeper. It is understood that the current inventory turnover of the company rose rapidly from 2015 to 2018. In addition, at present, Tianbao company also has some problems in inventory. It adopts the method of inventory according to the actual materials. Once the warehouse keeper has no strong sense of responsibility, even if the materials in the warehouse are taken away without permission, it is impossible to know, which brings great hidden danger to the company. At the same time, the company did not carry out strict approval on the collection of goods, which could easily lead to the unreasonable collection of materials.

4) Defective of cost control in sales: The salary cost of employees and the cost of turnover materials such as low value consumables are the main costs in the sales process. In the sales link, the cost is usually difficult to control, but in this link, the company's salesperson and the business face-to-face contact, their service level is directly related to the satisfaction of the business, and the data and information generated in this process can help the company better carry out the next decision. Because
Tianbao green food company does not pay attention to the statistics and analysis of various products and business demand information in the sales link, it is difficult to convey valuable information to the production and processing link, which is not conducive to determine the contribution of products to profits and affects the cost control in the sales link.

\section{ENTERPRISE COST CONTROL SOLUTIONS UNDER "BIG DATA"}

\section{A. Control cost through network platform}

The cost control of big data is mainly controlled by two parts: enterprise and supplier. For Tianbao company itself, the purchase of production materials is mainly based on the production requirements and the specific production prediction model. Because big data itself has the function of data prediction, which reduces the error rate of enterprise cost prediction; in the process of production cost accounting of Tianbao company, the traditional accounting method is mainly completed in the form of manual work, and there will be risks such as calculation errors, which will cause unnecessary losses for the enterprise, while in the process of data processing, big data calculation has more risks Less, can greatly improve the accuracy of accounting. In the process of supplier selection, because there are many suppliers, the company as the buyer has a strong right to negotiate the price. Big data technology through the network platform, completes the comprehensive comparison of the price of each supplier, so as to select the most advantageous supplier, so as to realize the control of enterprise procurement cost.

\section{B. Control production cost through logistics}

Delivering products to designated customers is one of the ways to control the cost of enterprises. In the process of production and sales, the transportation and circulation of raw materials and products is one of the important indicators to measure suppliers and sellers. In the process of logistics route selection, a multiple regression model is formed due to the joint action of route, cost, loss and many other factors, so the traditional accounting method is difficult to effectively account for it. The main function of big data is to analyze and process the data so as to reveal the relationship between the data. It realizes the analysis of multiple relationships through the use of algorithms, so as to provide suitable logistics routes for Tianbao company and reduce the production cost of the enterprise.

\section{Control of storage cost through simplification}

In the process of storage, Tianbao company can effectively determine the total amount of enterprise materials by establishing a perfect stock out and stock in model, but it is difficult to obtain effective control in the use of specific materials. Big data technology can work out the usage frequency and correlation of different materials according to the usage of different logistics, analyze them, so as to provide models and suggestions for the purchase behavior of enterprises, save the storage space and cost of enterprises, achieve the purpose of improving the productivity of workers, reasonably controlling the production cost, and realize the analysis of 
the data of previous years, so as to greatly reduce the cost Low cost.

\section{Control of sales cost through big data}

In the cost structure of Tianbao company, sales cost is one of the important components. After the product is produced, which channel to sell and how the middleman put the product into the market and get a good market response is one of the important issues in the cost control process of the company. In the face of the rapid development of the times, the traditional physical store sales model has a very limited sales influence, which is greatly affected by the spatial region, and the development of the network to a great extent makes up for the obstacles of the spatial region. In the process of processing network sales data, large amount of data and complex data structure are the main problems faced by data processing. The characteristics of big data can effectively solve the above problems and improve the economic benefits of enterprises.

\section{Conclusion}

Today, with the rapid development of information technology, the analysis and integration of big data can effectively improve the market competitiveness of enterprises. In the process of enterprise management, enterprise cost is an important factor restricting the development of enterprises. How to use big data technology to plan the cost of enterprises, and then help enterprises to manage and control the cost reasonably, is an important research direction at present. This paper expounds the function and control mode of "big data" for the cost control of Tianbao company. The research results show that: the application of big data technology for the cost control of enterprises is not only in the internal of enterprises, but also in the external planning of enterprises. Therefore, big data technology will become one of the most useful method to enhance the comprehensive strength of the enterprise.

\section{REFERENCES}

1. Wei Lizhi, fan Yanping. Construction of activity-based cost control system of manufacturing industry based on big data $[\mathrm{J}]$, practice and understanding of mathematics, 2017, 07, 56-60

2. Ouyang LAN. Analysis of cost management mode of food enterprises in the context of big data $[\mathrm{J}]$, economic and trade practice, 2017, 06, 65-70

3. Victor Meier scheenberg, Kenneth kukyer. Big data age [M], Hangzhou, Zhejiang People's publishing house, 2012

4. Sui Yunming. Discussion on Group Financial Sharing in the era of big data $[\mathrm{J}]$, Journal of Finance and accounting, September 34-38, 2014 